\title{
Equity Market Volatility Behavior in Sri Lankan Context
}

\author{
P. S. Morawakage ${ }^{1}$ and P. D. Nimal ${ }^{2}$ \\ ${ }^{\mathbf{1}}$ Department of Finance, Faculty of Commerce and Management Studies, \\ University of Kelaniya, Sri Lanka \\ morawakageps@kln.ac.lk \\ ${ }^{2}$ Department of Finance, Faculty of Management Studies and Commerce, \\ University of Sri Jayewardenepura, Sri Lanka
}

\begin{abstract}
Colombo Stock Exchange (CSE) in Sri Lanka is at its first level of emerging markets. Volatility of emerging markets are considered to be high and characterized by complex features. Therefore, this study focusses on examining the volatility behavior of Colombo Stock Exchange with advanced econometric models. Here GARCH, EGARCH and TGARCH models are used to capture the complex volatility features. It is observed that volatility clustering and leverage effect exists in Colombo Stock Exchange. Further, negative shocks creates more volatility compared to a positive shocks generated in the market. TGARCH model assuming student-t probability distribution function is more suitable to explain the volatility in Colombo Stock Exchange among the models described above according to the Akaike and Schwarz information criteria.
\end{abstract}

Keywords: Volatility, GARCH, EGARCH, TGARCH, CSE, Clustering, Leverage

\section{Introduction}

Financial markets are getting dynamic day by day. New instruments and trading methodologies such as derivative are introduced. Investor preferences are continuously changing over different markets. This scenario always encourages the academicians and practitioners in financial markets to innovate new models as well as validate, compare and contrast the existing models for the purpose of explaining different market phenomena. Stock market volatility is such a phenomenon which is concerned by investors, press and policy makers and closely monitored. Therefore, this study focusses on the stock market volatility and modeling in Sri Lankan context to provide some insights to the asset pricing and policy decisions.

\section{Background of the Study}

Arguably, volatility is one of the most important concepts in the whole of finance. Volatility, as measured by the standard deviation or variance of returns, is often used as a crude measure of the total risk of financial assets. Many value-at-risk models for measuring market risk require the estimation or forecast of a volatility parameter. The volatility of stock market prices also enters directly into the Black-Scholes formula for 
deriving the prices of traded options (Brook, 2008). Brook (2014) also explain modelling and forecasting stock market volatility has been the subject of vast empirical and theoretical investigation over the past decade or so by academics and practitioners alike. There are a number of motivations for this line of inquiry

It is very useful in finance to model return variance or volatility of major asset classes including equity, fixed income and foreign exchange. Understanding the behavior of the variance of the return process is paramount important for forecasting as well as pricing option type derivative instruments since the variance is a proxy for risk and thereby it will determine the required rate of returns of the investors. (Rachev, Mittnik, Fabozzi, Focardi, \& Jasic, 2007). The volatility is higher in emerging stock exchanges compared to matured markets (Michelfelder \& Pandya, 2005). Then, models developed in matured markets may not be suitable in emerging market context like Sri Lanka. Volatility of emerging markets is not easily captured by annualized standard deviation of equity index. And again volatility and returns are nonlinear as explained earlier. Linear structural (and time series) models such as linear regression, Auto Regressive Moving Average (ARMA) are also unable to explain a number of important features common to stock returns over a period of time. Such important features include Leptokurtosis, Volatility clustering or volatility pooling, Leverage effects (Brook, 2008). Therefore, studying "how to model the volatility in equity market?" is an ongoing problem due to the continuous improvements and complexity in emerging and frontier equity markets. This problem statement can be further investigated through the research questions given below.

- How volatility behave in Colombo Stock Exchange (CSE)?

- Which model is more appropriate to explain the volatility in Colombo Stock Exchange?

\subsection{Objectives of the Study}

In order to address the research questions stated above, followings research objectives are formulated.

Objective 01: To examine the volatility in the areas of clustering, leverage effects and sudden shocks in CSE

Objective 02: To Compare and contrast, GARCH, EGARCH and TGARCH models in explaining volatility in CSE

\subsection{Significance of the Study}

Different researchers have used different models and techniques to understand the volatility puzzle in different markets. They have highlighted pros and cons of each. This research also will try to understand the appropriateness of different models in explaining the volatility and return behavior of emerging markets. 


\section{Literature Review}

Volatility is up-and-down movement of the market. There are wide ranging compromises on what comprises stock market volatility and, on how to measure it. (Peiris \& Peiris, 2012). According to Schwert (1990) it is measured by standard deviation from the expectation. However Fayyad \& Daly, 2010 explain conditional volatility as a better measurement. At the same time, it is well known that emerging stock markets are characterized by high volatility (Bekaert \& Harvey, 1997; Aggarwal, Inclan, \& Leal, 1999; Michelfelder \& Pandya, 2005).

As Schwert (1990) mention that it is unclear whether the large volume of trading causes high volatility, or whether the high volatility and trading volume both reflect the arrival of important information. Then how investors react for negative information and positive information. Then negative information may have a different impact than a positive impact. This has been explained by Glosten, Jagannathan, \& Runkle (1993); Zakoian (1991) by introducing GJR model and TGARCH model respectively. According to their explanation risk and return is having a nonlinear relationship since negative shock create more volatility than a positive shock. Further Black in 1971 found there is a leverage impact in the equity return series suggesting a negative return would create more volatility than a positive return with the same magnitude.

Then how such volatility changes can be incorporated into scientific modeling. Modified time series analysis such as Autoregressive Conditional Hetroskedasticity (ARCH) proposed by Robert F Engle (1982), Generalized ARCH (GARCH) Tim Bollerslev (1986) and Exponential GARCH (EGARCH) proposed by Nelson (1991) are heavily used to model the volatility in many markets. Alberg, Shalit, \& Yosef (2008) support the view that both the ARCH and GARCH models capture volatility clustering and leptokurtosis in high volatile markets, but as their distribution is symmetric, they fail to model the leverage effect which is one of prominent characteristic of volatility. However many studies have found out that EGARCH is able to describe adequately the return process of the emerging markets under volatility.

In Sri Lanka there are few studies on stock market volatility. Study of Jaleel \& Samarakoon (2009) examines the impact of liberalization of the Sri Lankan stock market on return volatility. They specify GARCH and TGARCH models of volatility. The results show that liberalization of the market to foreign investors significantly increased the return volatility in the Colombo Stock Exchange and the market is more volatile to positive shocks than negative shocks indicating that no leverage effect exists in the market. (Jaleel \& Samarakoon, 2009) .

Therefore another confusion is the finding of Jegajeevan (2010). According to him, asymmetric EGARCH model has found the presence of asymmetric volatility indicating 
that the market reacts more to a negative than shock a positive shock of the same size (Jegajeevan, 2010). Same market two different researchers find that Leverage effect is not present. However Jaleel and Samarakoon (2009) has studied weekly returns whereas Jegajeevan (2010) has studied daily returns. Kumara, Upananda, \& Rajib, 2014 has done a study on dynamic properties of Colombo Stock Exchange under pre-war and post war condition. The have also employed TGARCH and EGARCH to capture the nonlinear aspect of volatility.

\section{Methodology}

Variance is the measurement of Volatility. However, literature and many econometric books suggest that if there is volatility clustering Conditional variance is the most suitable measurement of the volatility. Many emerging markets displays volatility clustering effect and hence conditional variance will be a determinant of volatility of the CSE. Daily returns are calculated based on the ASPI of the CSE during last ten years0. Then the daily return series is used to apply the ARCH type models using Eviews software.

\section{Hypotheses of the Study}

Following models will be used to achieve the first objective.

\section{GARCH $(1,1)$ Model}

Here we assume the current level of volatility tends to be positively correlated with its level during the immediately preceding periods (Brook, 2008). The GARCH model allows the conditional variance to be dependent upon previous own lags, so that the conditional variance equation in the simplest case is now

\section{Variance Equation}

$$
\eta_{\mathrm{it}}=\alpha_{0}+\alpha_{\mathrm{q}} \varepsilon_{i t-q}^{2}+\varnothing_{\mathrm{p}} \eta_{\text {it-p }}
$$

If $\alpha_{\mathrm{q}}$ is significant there is an impact from previous shocks on the conditional variance. As well as if $\emptyset_{\mathrm{p}}$ is significant there is an impact from the previous conditional variance on the contemporaneous conditional variance. That means there is volatility clustering effect in the selected markets. $t$ statistics and $p$ value will be used to test the hypothesis under 5\% significant levels. Then the hypothesis will be;

$$
\begin{aligned}
& \mathrm{H}_{0}: \emptyset_{\mathrm{p}} \leq 0 \\
& \mathrm{H}_{1}: \emptyset_{\mathrm{p}}>0
\end{aligned} \longrightarrow \quad \text { Hypothesis } 01
$$

If $\emptyset_{\mathrm{p}}$ is greater than zero, it indicates that there is a clustering effect since it is a positive relationship. Therefore $\mathrm{H}_{0}$ should be rejected and $\mathrm{H}_{1}$ should be accepted at $5 \%$ significant level. 
Leverage effect will be captured through the EGARCH model and nonlinear impact will be captured through TGARCH model as follows.

\section{EGARCH model specification}

$$
\ln \eta_{\mathrm{t}}=\omega_{0}+\omega_{1} \ln \eta_{t-1}+\lambda \frac{\varepsilon_{t-1}}{\sqrt{\eta_{t-1}}}+\omega_{2}\left[\frac{\left|\varepsilon_{t-1}\right|}{\sqrt{\eta_{t-1}}}-\sqrt{\frac{2}{\pi}}\right]
$$

If $\lambda$ parameter is negative and significant it is said that leverage effect exist where a negative return would create more volatility than a positive return with the same magnitude (Black 1971).

Therefore following hypothesis will be tested.

$\mathrm{H}_{0}: \lambda \geq 0$

$\mathrm{H}_{1}: \lambda<0$

Hypothesis 02

\section{TGARCH or GJR Model specification}

$$
\eta_{\mathrm{t}}=\alpha_{0}+\alpha_{1} \varepsilon_{t-1}^{2}+\emptyset_{1} \eta_{\mathrm{it}-1}+\gamma \varepsilon_{t-1}^{2} I_{t-1}
$$

Where $I_{t-1}=1$ if $\varepsilon_{t-1}<0 \&=0$ otherwise

Slope parameter $\gamma$ should be positive and significant then if there are negative shocks $\left(\varepsilon_{t-1}<0, I_{t-1}=1\right)$ there is a more positive impact on the conditional variance other than a positive shock $\left(\varepsilon_{t-1}>0, I_{t-1}=0\right)$ (Zakoian, $1991 \&$ Glosten, et al., 1993). Then nonlinear impact can be observed in the data set. Therefore following Hypothesis will be tested.

$$
\begin{aligned}
& \mathrm{H}_{0}: \gamma \leq 0 \\
& \mathrm{H}_{1}: \gamma>0
\end{aligned} \longrightarrow \text { Hypothesis } 03
$$

Akaike and Schwarz information criteria will be used to select the best model appropriately in order to achieve the second objective. According the both criteria lowers value will provide the better model.

\section{Findings of the Study}

The mean daily return was $0.076 \%$ for Sri Lanka market. The sample variances of $1.21 \%$ and the standard deviations of $1.1 \%$ of the return distributions measure the volatility of Sri Lanka CSE. There is an indication of negative skewness (-0.541) in CSE ASPI which indicates that the lower tail of the distribution was thicker than the upper tail. It means that the indices decline occur more often than its increases. The kurtosis coefficient is positive, having high value for the return series (14.54) that is the pointer of leptokurtosis or fat taildness in the underlying distributions. 
Sri Lanka Stock market return series exhibit negative skewedness and excess kurtosis. The Jarque -Bera test rejects the normality hypothesis for Sri Lanka returns probability distribution function (pdf) as test statistic $(13,488)$ is larger and $\mathrm{p}$ value is closer to zero. This scenario rejects the normality assumption in the ASPI return series due to the high kurtosis also confirm the non-normality of the returns series. Stock and stock market return pdf's are highly skewed and leptokurtic. Therefore a flexible parameter pdf is required that can accommodate varying levels of skewness and kurtosis that typically characterize stock return pdf's (Michelfelder \& Pandya, 2005). Theodossiou, 1998 suggested if it is the case we can assume Skewed Generalized-t Distribution for the data processing. Further, Baillie \& DeGennaro, 1990 has suggested a conditional student- $t$ Distribution. They have mentioned Bollerslev (1987) and Baillie \& Bollerslev (1989) have provided example for the $t$ distribution approach. Therefore, this investigation uses the Generalized Error Distribution (GED) and student $t$ distribution to deal with the anomalies in the financial data series.

Liu et al. (2009), Alberga et al. (2008), and Hien (2008) finds that volatility forecasts by the GARCH-SGED model are more accurate than those generated using the GARCH-N model, indicating the significance of both skewness and tail-thickness in the conditional distribution of returns (Lim \& Sek, 2013).

\section{A. Stationerity test}

Augmented Dickey-Fuller Test statistics for both markets are significant at $1 \%$ level suggesting there is not a unit root in the return series. Therefore the return series can be processed and tested for ARCH effect.

\section{B. ARCH Effect}

ARCH-LM test is carried out and statistically significant which indicates the presence of ARCH effect in the residuals of mean equation of Sri Lanka ASPI return series. Then ARCH type models can be estimated to analyze the volatility and its impact on equity premium in the selected markets.

\section{Volatility Clustering}

GARCH 1, 1 model capture the volatility clustering of CSE. It is observed that conditional volatility parameter $\varnothing 1$ is significant and positive at $1 \%$ level suggesting volatility clustering effect assuming both probability distribution functions.

\section{Asymmetric and nonlinear volatility in emerging markets}

If the corresponding $p$ value of $\lambda$ is small and coefficient is negative, leverage effect is present as discussed under methodology. In CSE, it is highly significant at $5 \%$ level and negative suggesting there is a leverage effect under both $t$ and GED distributions. If leverage effect is present there is an asymmetric impact on volatility. That means there is a negative correlation between the past return and the future 
volatility of return where a positive shock has a less effect on the conditional variance compared to a negative shock. If return is lower (negative) higher the volatility and if return is high (positive) lower the volatility.

TGARCH parameters are also significant and positive at $1 \%$ level suggesting negative innovations have more impact than positive innovations.

\section{Discussion of Findings}

Many emerging markets displays the volatility clustering (Kumara, et al., 2014; Michelfelder \& Pandya, (2005). This study is also consistent with many scholars finding as CSE displays the volatility clustering. However, there are contradictory findings on asymmetric and nonlinear volatility.

Jaleel \& Samarakoon, 2009 finds that Sri Lanka market is more volatile to positive shocks than negative shocks indicating that no leverage effect exists in the market. At the same time Jegajeevan,2010 argues asymmetric EGARCH model finds that the presence of asymmetric volatility indicating that the market reacts more to a negative shock than a positive shock of the same size. Complying with Jegajeevan, 2010 this study also provides evidence of leverage effect in Sri Lanka Market. Further, Sri Lanka stock market is significantly affected by the negative innovations than positive innovation as per TGARCH parameters.

TGARCH model is the best for the Sri Lanka market according to the Akaike and Schw information criteria among GARCH, EGARCH and TGARH. Many researchers (Michelfelder \& Pandya, 2005; Bekaert \& Harvey, 1997) have rejected GARCH as a better model to explain the volatility in emerging markets. However EGARCH has been accepted as a better model to describe the volatility in emerging markets (Michelfelder \& Pandya, 2005; Fung \& Poon, 2000; Lim \& Sek, 2013). TGARCH also has been accepted by some researchers (Wu, 2010; Jaleel \& Samarakoon, 2009; Kumara, et al., 2014).

\section{Conclusion}

First objective of the study is to examine the behavior of the volatility in CSE. Then, it is concluded that both clustering effect and leverage effect exist in CSE. That means "large return changes tend to be followed by large return changes, of either sign, and small return changes tend to be followed by small return changes as clustering effect exists and the tendency for volatility to rise more following a large price fall than following a price rise of the same magnitude as leverage effect exist.

Second objective is to select a best model which fits and explains the volatility in CSE return series. TGARCH model assuming student-t distribution is more suitable to explain the volatility in CSE. This suggests that there is a more positive impact on the 
conditional variance or the volatility from the negative shocks other than a positive shock in CSE.

\section{References}

Aggarwal, R., Inclan, C., \& Leal, R. (1999). Volatility in Emerging Stock Markets. The Journal of Financial and Quantitative Analysis, 33-55.

http://dx.doi.org/10.2307/2676245

Alberg, D., Shalit, H., \& Yosef, R. (2008). Estimating stock market volatility using asymmetric GARCH models. Applied Financial Economics, 1201-1208. http://dx.doi.org/10.1080/09603100701604225

Backus, D. K., \& Gregory, A. W. (1993). Theoritical Relations between risk premium and conditional variances. Journal of Business and Economic Statistics, Vol.11, No.2, 177 185. http://dx.doi.org/10.2307/1391369

Baillie, R. T., \& DeGennaro, R. P. (1990). Stock Returns and Volatility. The Journal of Financial and Quantitative Analysis, Vol. 25, 203-214. http://dx.doi.org/10.2307/2330824

Bekaert, G., \& Harvey, C. R. (1997). Emerging Equity Market Volatility. Journal of Financial Economics, 29-77. http://dx.doi.org/10.1016/S0304-405X(96)00889-6

Bekaert, G., \& Wu, G. (2000). Asymmetric Volatility and Risk in Equity Markets. The Review of Financial Studies, Vol. 13, 01-42. http://dx.doi.org/10.1093/rfs/13.1.1

Bollerslev, T. (1987). A Conditionally Hetroskedastic Time Series Model for Speculative Prices and Rates of Return. The Review of Economics and Statistics, 542-546. http://dx.doi.org/10.2307/1925546

Brook, C. (2008). Introductory Econometrics for Finance. Cambridge: Cambridge University Press. http://dx.doi.org/10.1017/CBO9780511841644

Claessen, S., Dasgupt, S., \& Glen, J. (1995). Return Behavior in Emerging Stock Markets. The World Bank Economic Review, Oxford Journals, 131-151. http://dx.doi.org/10.1093/wber/9.1.131

Claessen, S., Dasgupta, S., \& Glen, J. (1995). Return Behavior in Emerging Stock Markets. The World Bank Economic Review, Vol 9, 131-151. http://dx.doi.org/10.1093/wber/9.1.131

Elton, E. J. (1999). Expected Return, Realized Return, and Asset Pricing Tests. The Journal of Finance, 1199-1220. http://dx.doi.org/10.1111/0022-1082.00144

Fayyad, A., \& Daly, K. (2010). The Volatility of Market Returns: A Comparative Study of Emerging versus Mature Markets. International Journal of Business and Management, 24-36. http://dx.doi.org/10.5539/ijbm.v5n7p24 
Glosten, L. R., Jagannathan, R., \& Runkle, D. E. (1993). On the Relation between the Expected Value and the Volatility of the Nominal Excess Return on Stocks. The journal of Finance, 1779-1801.

http://dx.doi.org/10.1111/j.1540-6261.1993.tb05128.x

Jaleel, F. M., \& Samarakoon, L. P. (2009). Stock market liberalization and return volatility: Evidence from the emerging market of Sri Lanka. Journal of Multinational Financial Management, 409-423.

http://dx.doi.org/10.1016/j.mulfin.2009.07.006

Jegajeevan, S. (2010). Return Volatility and Asymmetric News Effect in Sri Lankan Stock Market. Economic Research Department Central Bank of Sri Lanka Staff Studies Volume 40 Numbers $1 \& 2,37-57$.

Kim, C. J., Morley, J. C., \& Nelson, C. R. (2004). Positive Relationship between Stock Market Volatility and the Equity Premium? Journal of Money, Credit and Banking, Vol. 36, 339-360. http://dx.doi.org/10.1353/mcb.2004.0055

Kumara, U., Upananda, W. A., \& Rajib, M. S. (2014). Impact of Ethnic War on Dynamic Properties of Stock Return in Colombo Stock Exchange of Sri Lanka. International Conference on Management and Economics (pp. 218-227). Faculty of Management and Finance, University of Ruhuna, Sri Lanka.

Theodossiou, P. (1998). Financial Data and the Skewed Generalized T Distribution.

Management Science/Vol 44, 1650-1661. http://dx.doi.org/10.1287/mnsc.44.12.1650

Wang, D. C., \& Mykland, P. A. (2012). The Estimation of Leverage effect with High Frequency Data. Journal of the American Statistical Association. 